\title{
Emotional Life of People with Addictive Disease
}

\section{Roman Procházka1, Karel Nešpor ${ }^{2}$}

1 Department of psychology. Lorem ipsum dolor sit amet, consectetur adipiscing elit. Fusce est ligula, mattis commodo faucibus eget, mattis malesuada sem. Palacky University Olomouc

2 Psychiatric Hospital Bohnice, Prague, Czech Republic.

\section{Summary}

Addicted individuals are often less aware of their emotions. However, in these people strong emotions often occur and act as a trigger for addictive behavior or are induced by it. Improving realization of emotions and emotional management is an important part of the treatment of addictive disease and can be combined with strengthening motivation. Risk emotions, craving and stress can be managed in the same or similar ways. Good emotion management facilitatescoping with cravings and vice versa. Specific procedures are discussed in more detail other literature (Nešpor, 2017, 2013). In order to use them, the addict must, however, be aware of the risky mental state. The aim of our work is to point out possible connections between alexithymia and alcohol addiction. Another aim of our work is also to briefly define the referenceareas of the related emotional schemes and practical recommendations for improving awareness of one's own emotions and incipient craving.

\section{Keywords}

Class patent, taciti sociosqu, ad litora, torquent per conubia, nostra per inceptos, himenaeos

\section{Alexithymia}

Alexithymia can be defined as a deficit in the processing and regulation of emotions, leading to maladaptive styles of emotional regulation (Procházka, 2009). It represents a verbal and nonverbal disorder of cognition of emotions and translations of emotions into words. Alexithymia can also be seen as a certain internal mechanism of pushing aside hurtful or painful negative feelings, but without their complete separation from consciousness. Alexithymia is therefore characterized by the presence of an inability to realize and describe one's emotions. This is also related to the impaired ability to distinguish emotional states of other people. Alexithymia poses a risk factor for psychosomatic and addictive diseases (e.g. Cruise, Becerra, 2018; Gao et al., 2018) This risk factor may play an important role in the genesis of addictions, e.g. alcohol addiction (DeRick, Vanheule, 2006, de Timary et al., 2008). In alcohol-dependentindividuals, alexithymia was identified in 45-67\% of probands (Evren et al., 2008; Sauvage, Loas, 2006; Uzun et al., 2003). It can be argued that impaired ability to be aware of emotional states may be the result of an addictive disease, therefore not only one of the possible causes. In any case, this is a factor that is important in prevention and treatment.

From the point of view of the study of alexithymia as a certain risk factor for addiction development, it is assumed that the expected effect of alcohol is the reduction of tension and modulation of affective regulation, which are bothexpressed in the manifestations of alexithymia. Furthermore, alexithymia as well as unsatisfactory attachment is seen as a risk factor that plays a role in the formation and development of alcohol addiction (Haviland, Warren Riggs, 2000; Vungkhanching et al, 2004). In an alcohol addict with alexithymia, the reason for drinking may be based on the fact that alcohol use represents a coping mechanism of emotional selfregulation that is influenced by alexithymia and positively modulated by alcohol use (De Rick, Vanhuele, 2007b; Thorberg, Lyvers, 2006a).

\section{Craving, its similarity and combination with emotions}

Craving is a key feature of addictive diseases (Nešpor, 2017) and at the same time it resembles strong risk emotionsin many ways. Like emotion, craving is accompanied by stress, makes it difficult to perceive oneself and the surroundings, worsens judgement and has a strong motivational effect, i.e. weakens self-control. Weakened self-control is, as we know, another key feature of addictive diseases.

The combination of strong emotion and craving has a synergistic effect, i.e. it causes even more stress, and further weakens the selfcontrol. This often happens in the case of addictive disease relapse. At the beginning of the disease there is a strong, though sometimes unaware craving. This craving increases with the addictive behavior and isaccompanied by strong emotions. To illustrate the situation, we sometimes refer to this state as "a joy of an idiot that lasts five minutes." There are also the feelings of guilt, depression, irritability, anger, and fear of the futureaccompanied by stress and negative emotions caused by the reaction of the people around the addict or health problems.

This is not a hypothetical construction, but a fact. We often talk to addicts about the emotions that have occurred in connection with addictive behavior in order to strengthen their motivation. And the addicts confirm the states mentioned above.

An important area is the awareness or recognition of craving. The presence of alexithymia can make it difficult or complicated to treat drug addicts. In the research conducted by C. Evren et al (2009), the existence of a relationship between alexithymia, dissociation and craving in alcoholaddicts was confirmed. The discussion of their research shows that craving is a negative emotional state that has a burdensome character on the individual and alexithymia represents a response to this burden. 
Awareness of one's own emotions and life situation is not easy or pleasant for the addicts at the beginning of abstinence. Previously they tended to avoid unpleasant mental states and life problems and now they are fully exposed to them. The situation changes with continued abstinence: emotions clear up andsome problems are gradually being solved.

\section{How to improve awareness of emotions and incipient craving}

Early awareness of emotions and craving is important for their better management. Incipient craving or risk emotions can be managed better, for example by reducing the effect of the stimulus that has caused them. Experience with the treatment of alexithymia proves that the emotional awareness can be improved. In the field of addictive diseases, Kamboj et al. (2007) used awareness training with very good results. In abstaining addicts, better emotional awareness occurs relatively quickly as a result of treatment and due to longer abstinence. This is also related to a greater ability to experience positive emotions, such as "to enjoy the little things." The following overview summarizes some of the factors that weaken or improve emotional awareness.

\section{Emotional schemas}

It this section, we will focus on emotional schemas in the context described above. The model of the emotional schemas is based on the beliefs about one's own emotions and emotions of others, as well as the strategies to manage them. The emotional schema model is a cognitive model of evaluating the emotions of one's own and the emotions of others. It includes interpretations, assessments, assignments, and other cognitive evaluations of emotions. It also includes emotional regulation strategies, both functional and dysfunctional.In particular, it focuses on sociocognitive models of emotional evaluation in the context of emotional schemas (it does not emphasize thinking and behavior), thus exploring more how people react, experience and express their emotions (Leahy, 2015). In emotional schemas, there are 14 dimensions for conceptualizing, emotional evaluating and emotional responses. These include: dimension of duration, uncontrollability, comprehensibility, consensus, guilt and shame, demand forrationality, simplistic view of emotions, highervalues, expression, validation, acceptance, accusation, numbnessand mental ruminations (Leahy, 2015). When working practically with emotional schemes, we focus on both the dimensions mentioned above and the basic areas, i.e.:

- Primary emotional concern

- Expression of emotion

- Beliefs about emotions

- Emotional socialization

- Problematic and maladaptive emotion regulation strategies

Primary emotional concern: this area is based on an ideathat individuals coming into e.g. therapy tend to have rather increased tendency to pay attention to only one emotion or only a few emotions, and they consider the others unimportant - e.g. preferring their own anxiety of suffering (to delight in one's own suffering). In the therapeutic work with emotions, it is therefore advisable to monitor what emotions the individual prefers and what emotions he or she avoids.
Expression of emotion: this area is based on differences in expression of emotions. In some clients, we encounter open expression of emotions, while in others, their emotions are unclear, dull and bland. It is also advisable to observe the discrepancies between verbal and nonverbal emotional expressions.

Beliefs about emotions: this area focuses on what the clients think about emotions - both their own and emotions of others. Whether they can realize the right to their emotions and the emotions of others, the different emotional experience of other people, the need to express oneself emotionally.

Emotional socialization: this area significantly expands the area of beliefs about emotions. We focus on expressing emotions in clients when they were children, on expressing the emotions of their parents and other important persons, on how they reacted to emotions, how the emotions were evaluated, expected, punished, etc.

Problematic and maladaptive emotion regulation strategies: this area focuses on evaluation of how the clients have reacted to their emotions since childhood, how they think about them, what they do with their emotions, how they treat them, what their coping strategies are.

\section{What improves and worsens awareness of emotions}

Worsens: Alcohol, other addictive substances, gambling and craving. Fatigue and exhaustion. Excessive stress and rush. Pain and physical or mental illness. Strong emotions make it difficult to perceive weaker emotions and cravings, just as strong noise reduces the ability to recognize subtle tones.

Improves: Abstinence and avoidance of stimuli that cause cravings. Adequate rest and balanced way of life. Various forms of psychotherapy and continuous aftercare. Training, e.g. recording of inner silence meditation is freely available at www.drnespor.eu. Relaxation techniques and yoga. Working with diary and other aids. Training of recognizing nonverbal communication and development of hearkening skills. Calm and safe environment. Enough time. Actively or passively cultivated arts (music, drawing, creative writing, etc.)

Notes on the training of better perception of emotions and cravings

- $\quad$ The above-mentioned techniques should be modified for this purpose.E.g. when writing a diary, it is advisable to focus more on emotions and less on factual description. This also applies to art therapy, music therapy or the above-mentioned meditations of inner silence.

- Awareness of emotions can be combined with strengthening of motivation. The following interview is a model interview with a patient who insists on continuing to go to a high-risk society after treatment.

Therapist: "Let's say you would go there. What do you think you would fell when looking at what's going on there?"

Patient: "I guess I would feel craving."

Therapist: "How does it manifest in you?"

Patient: "I feel tense and I want to get wasted."

Therapist: "That is probably quite annoying, even if you can manage your craving, isn't it?" 
- Awareness of the subtle positive emotions, which, unlike the risky ones, soothe,also hasa motivating effect. We usually include this element e.g. at the end of the after-treatment groups. Those who are present can, for example, answer questions like:

$\circ$ When sober, what makes you feel better?
$\circ \quad$ What has pleased you recently?
$\circ \quad$ What benefits of sobriety have you realized?

\section{Discussion:}

As we already mentioned in the text above, alexithymia can be viewed form the perspective of disturbed mentalization (symbolization) of feelings in the consciousness, which results in less differentiatedemotional states that areexperienced as somatic tension or physical discomfort. Because of the cognitive and personality conspicuity of these people with alexithymia, the early concepts of alexithymia were associated with the terms "infantile personality" (Ruesch, 1948) and "operational thinking” (M'Uzan, 1963). In the current state of scientific knowledge, alexithymia is classified as a borderline concept of psychosomatic medicine due to the uncertainty of its etiology. Thus, it represents a so-called "heuristic construct" that is suitable for exploring the role of personality and emotions in the development of somatic diseases (Taylor, 1997). Current research findings suggest that the presence of alexithymia has been demonstrated in several clinical disorders such as: somatoform disorders, panic disorder, depression with dominance of vital and somatic symptoms, post-traumatic stress disorders and eating disorders (Vanheule, 2008; Frewen, Pain, Dozois, Lanius, 2006; Hund, Espelage, 2005; Mueller, Buehner, 2006; Speranza, Laos, Wallier, Corcos, 2007; Taylor, Bagby, Parker, 1997; Vanheule, Desmet, Verhaeghe, Bogaerts, 2007).

In alexithymia, the risk factor may also play an important role in the genesis of addictions to alcohol and other psychoactive substances. It can be assumed that the relationship between alexithymia and alcohol addictionis based on the fact that people with alexithymia do not feel at ease in the company of others and can therefore use alcohol as a coping mechanism (Procházka, 2011). Thus, by using alcohol they improve the perception of their interpersonal functioning. This mechanism of coping with interpersonal functioning can be observed across the spectrum of other substance addictions in individuals who experience alexithymic characteristics. We can critically state, that the relationship between alexithymia and addiction needs to be further investigated and verified in other studies.We also need to find the possible connections between alexithymia andaddiction theories (biological, psychoanalytic, behavioral integrative and others), which is currently pushed to the background due to the boom in neuroscience addiction theories. Another important question about alexithymia is whether it is a personality trait or an individual's reaction to a relative problems or disease. Conclusions that have been drawn from the research suggest that alexithymia appears to be a stable personality trait in neurotic disorders (Pandey, Mandal, 1996), depressions (Hendryx, Haviland, Shaw, 1991) and anxieties (Bagby, Taylor, Atkinson, 1988). Despite these research findings, it is still uncertain whether alexithymia is a unique personality trait or a part of a state of experienced anxieties, depressions, somatic problems, or florid psychopathology (Hendryx et al. 1994). Regardless of the disunity of opinion concerning the classification of alexithymia, we believe that in the therapeutic praxis it is important to work with emotional awareness and emotional schemas that have their development rooted in children's experiences and with the quality of the relationship attachment. We believe that it is very important to further investigate the issues of emotional life in individuals addicted to psychoactive substances (as mentioned above), but to us, it seems more beneficial to find the resulting options of treatment and psychotherapy.At present, however, we are more able to describe and organize these problems into other hypotheses and questions, but in fact we do not know how to help a person with alexithymia for example from painful emotional experiencing and mentalization disorders. It seems therefore appropriate to find and verify practical procedures in treatment of these problems in controlled studies instead of constantly statistically demonstratethe relations and non-relations between alexithymia and other spectrum of human behavior in normal or pathological experiencing.

\section{Conclusion:}

In this article we ponder on the relationship between alexithymia and alcohol addiction. We can state that there are many research studies confirming this relationship (but also a relationship to other areas of clinical disorders). Overall, however, despite the clinical relevance of alexithymic manifestations, it is not possible to satisfactorily answer the question whether alexithymia is a condition or a personality trait. We believe that instead of finding other quantitative and qualitative relations and links between various conditions and disorders, it is appropriate to identify and verify effective treatment options. To summarize this issue, it is possible to say that in the current state of diagnostic knowledge we can often find ourselves in situations where we are able to describe a person, his or her personality, life etc. in an exhaustive way (sometimes even in a way bordering with aclinical impression) but sometimes we really do not know what to do with this person in practical medical care.

\section{References}

Cruise, K.E.,\& Becerra R. (2018). Alexithymia and problematic alcohol use: A critical update. Addict Behav. 77, 232-246.

De Rick, A., \& Vanheule, S. (2006). The relationship between perceived parenting, adult attachment style and alexithymia in alcoholic inpatients. Addictive Behaviors, 31(7), 1265-1270

De Rick, A., \& Vanheule, S. (2007). Attachment styles in alcoholic inpatients. European Addiction Research, 13(2), 101-108.

De Timary, P., Luts, A., Hers, D., \& Luminet, O. (2008). Absolute and relative stability of alexithymia in alcoholic inpatients undergoing alcohol withdrawal: Relationship to depression and anxiety. Psychiatry Research, 157, 105-113.

Evren, C., Kose, S., Sayar, K., Ozcelik, B., Borckardt, J. P., Elhai, J. D., et al. (2008). Alexithymia and temperament and character model of personality in alcohol dependent Turkish men. Psychiatry and Clinical Neurosciences, 62(4), 371-378.

Evren, C., Durkaya, M., Celik, R., Dalbudak, E., Cakmak, D., \& Flannery, B. (2009). Relationship of alcohol craving with alexithymia and dissociation in male alcohol dependent inpatients. Anatolian Journal of Psychiatry, 10:165-173.

Frewen, P.A., Pain, C., Dozois, D.J.A., \& Lanius, R.A. (2006). Alexithymia in PTSD: Psychometric and FMRI studies. Annals of the New York Academy of Sciences, 1071, 397-400. 
Gao, T. Li. J., Zhang, H., et al. (2018). The influence of alexithymia on mobile phone addiction: The role of depression, anxiety and stress. J Affect Disord., 225,761-766.

Haviland, M. G., Warren, W. L., \& Riggs, M. L. (2000). An observer scale to measure alexithymia. Psychosomatics: Journal of Consultation Liaison Psychiatry, 41(5), 385-392

Hendryx, M.S., Haviland, M.G., \& Shaw, D.G. (1991). Dimensions of alexithymia and their realtionships to anxiety and depression. Journal of Personality Assesment, 56,227-237.

Hendryx, M.S., Haviland, M.G., Shaw, D.G., \& Henry J. (1994).Alexithymia in women and men hospitalized for psychoactive substance dependence. Comprehensive Psychiatry, 35,124-128.

Hund, A.R., \& Espelage, D.L. (2005). Childhood sexual abuse, disordered eating, alexithymia and general distress: A mediation model. Journal of Counseling Psychology, 52, 559573.

Leahy, R. L. (2015). Emotional schema therapy. Guilford Publications.

Kamboj, S.K., Irez, D., Serfaty, S., et al. (2017). Ultra-Brief Mindfulness Training Reduces Alcohol Consumption in At-Risk Drinkers: A Randomized Double-Blind Active-Controlled Experiment. Int J Neuropsychopharmacol., 20(11):936-947.

Mueller, J., \&Buehner M. (2006). Twofacetsof nonexpressionofemotions:

Relationshipsbetweendimensionsofalexithymia and therepressivecoping style. Personality and IndividualDifferences, 41, 1337-1347.

M’Uzan, M. de (1976). Contre-transfert et systèmeparadoxal. Rev. Franç. Psychanalyse, 38/2.

Nešpor, K. (2017). Bažení (craving): klíčový znak návykových nemocí a způsoby, jak ho zvládat. Practicus, 16, 25-26.

Nešpor, K. (2013).Sebeovládání: stres, rizikové emoce a bažení lze zvládat. Praha: Portál.

Pandey, R., \& Mandal, M.K. (1996). Eysenckian personality dimension and alexithymia: Examining the overlap terms of percevied autonomic arousal. Personality and Individual Differences. 20,499-504.

Procházka, R. (2009). Soudobékoncepce alexithymia. Epsychologie, 3(3)
Procházka, R. (2011). Disociace, alexithymie a self u lidízávislýchnaalkoholu. Olomouc: UP.

Ruesch, J. (1984). The infantile personality. The core problem of psychosomatic medicine. Psychosomatic Medicine, 10, 134144.

Sauvage, L., \&Loas, G. (2006). Criterion validity of Bermond-Vorst Alexithymia Questionnaire - 20 form B: A study of 63 alcoholic subjects. Psychological Reports, 98(1), 234-236

Speranza, M., Laos, G., Wallier, J., \&Corcos, M. (2007).

Predictivevalueofalexithymia in patinetwitheatingdisorder: A 3-yearprospective study. JournalofPsychosomaticResearch, 63, 365-370.

Taylor, G. J., Bagby, R. M., \&Parker, J. D .A. (1997). Disordersofaffectregulation. Cambridge, UK: Cambridge University Press.

Thorberg, F. A., \&Lyvers, M. (2006). Attachment, fearofintimacy and differentiationofselfamongclients in substance disordertreatmentfacilities. AddictiveBehaviors, 31(4), 732 737.

Uzun, A. Z., Ates, A., Cansever, A., \&Ozsahin, A. (2003). Alexithymia in male alcoholics: Study in a Turkish sample. Comprehensive Psychiatry, 44(4), 349-352.

Vanheule, S. (2008). ChallengesforAlexithymiaResearch: A Commentary on TheConstructofAlexithymia: AssociationsWithDefenseMechanisms. Journalofclinical psychology, 64(3), 332

Vanheule, S., Desmet, M., Verhaeghe, P., \&Bogaerts, S. (2007) Alexithymicdepression: Evidence for a depresion subtype? Psychotherapy and Psychosomatics, 76, 135-136.

Vungkhanching, M., Sher, K. J., Jackson, K. M., \&Parra, G. R. (2004) Relationofattachment style to familyhistoryofalcoholism and alcohol use disorders in early adulthood. Drug and Alcohol Dependence, 75(1), 47-53.

PhDr. Mgr. Roman Procházka, Ph.D.

roman.prochazka@upol.cz

MUDr. Karel Nešpor, CSc

drnespor@gmail.com,www.drnespor.eu

Figure XY. Popis obrázku 